progression, our work suggests that the analysis of synovial MCs could help to identify patients at high risk of progression in radiographic damage, warranting further investigations to confirm the association of MCs with the development of joint damage and their direct contribution to bone erosion, possibly via a RANKL-mediated activation of osteoclasts.

Disclosure of Interest: None declared

DOI: 10.1136/annrheumdis-2017-eular.6393

\section{FRI0031 DNA OXIDASE ENZYME TET3 EXACERBATES SYNOVIAL INFLAMMATION AND BONE DESTRUCTION}

A. Kawabe ${ }^{1}$, K. Naknao ${ }^{1}$, K. Sakata ${ }^{1,2}$, K. Yamagata $^{1}$, S. Nakayamada ${ }^{1}$, Y. Tanaka ${ }^{1} .{ }^{1}$ The First Department of Internal Medicine, University of Occupational and Environmental Health, Japan, Kitakyushu; ${ }^{2}$ Mitsubishi Tanabe Pharma, Yokohama, Japan

Background: In rheumatoid arthritis (RA), fibroblast-like synoviocytes (FLSs) play an important role in joint destruction. We have shown a disease-specific DNA methylation pattern in RA patient-derived FLSs (RA FLSs). In 2009, active demethylation enzymes, Ten-Eleven translocation (TET) $1 / 2 / 3$, were demonstrated. However, little is known about the role of the TET protein family in RA FLSs

Objectives: The aim of this study was to examine the role of the TET protein family in the pathological process of RA from an in vivo perspective with a mouse model, and from an in vitro perspective using human synovial tissue.

Methods: K/BxN serum-induced arthritis was induced in Wild-type (WT) and TET3 heterozygous-deficient $\left(\right.$ TET3 $\left.^{+/}\right) \mathrm{C} 57 \mathrm{BL} / 6$ mice. Synovial tissues were obtained from patients with RA and Osteoarthritis (OA) who had received joint replacement surgery. FLSs were transfected with siRNA and knocked down (KD). Gene expression was determined by $\mathrm{qPCR}$ and protein expression by western blot and immunostaining. 5-hydroxymethylcytosine $(5 \mathrm{hmC})$ was determined by dot blot and hMeDIP assay. Cell migration were assessed using a scratch assay. Results: TET3 was expressed in particularly infiltrative synovial areas in $\mathrm{K} / \mathrm{BxN}$ WT mice. The arthritis score of $\mathrm{K} / \mathrm{BxN}-\mathrm{TET3^{+/- }}$ was not increased after day 8. Histologically, synovial inflammation and proliferation, and bone destruction were significantly suppressed in the $\mathrm{K} / \mathrm{BxN}-\mathrm{TET3^{+/- }}$ mice. In the RA synovial membrane, TET3 was more highly expressed in RA than in OA. In cultured FLSs, the expression of TET3 mRNA tended to be slightly higher in RA than in OA. After $2 \mathrm{~h}$ of stimulation with various cytokines, the expression level of TET3 mRNA was increased by stimulation with TNF $\alpha$, interleukin (IL)-1, or IL-17. Assessment of the protein expression of TET3 after stimulation by TNF $\alpha$ using extracted intranuclear proteins of FLSs showed an increase in the expression level of TET3 protein over time. Similarly, the expression level of $5 \mathrm{hmC}$ was increased after stimulation by TNF $\alpha$. Next, the function of TET3 in the FLSs was examined using TNF stimulation follwoing TET3-KD. A scratch assay of cell migration and invasion demonstrated that the TNF $\alpha$-dependent migration and invasion of FLSs was completely inhibited by TET3-KD. The protein levels of CCL2 were strongly induced by TNF $\alpha$ stimulation, and inhibited by TET3-KD. In addition, flow cytometry of the expression of intercellular adhesion molecule-1 (ICAM-1) revealed that the expression of ICAM-1 was TNF $\alpha$-dependent and was inhibited by TET3-KD. Assessment of gene expression changes showed that the induction of TNF $\alpha$-dependent CCL2 and ICAM-1 mRNA expression was significantly inhibited by TET3-KD. Subsequently, although $5 \mathrm{hmC}$ level on the ICAM-1 promoter was increased by TNF stimulation, it was strongly inhibited by TET3-KD.

Conclusions: In vivo, the arthritis and bone erosion were significantly decreased in the $\mathrm{TET3}^{+/-}$mice. In vitro, TET3 was induced by inflammatory cytokine stimulation, and TET3 knockdown inhibited the cytokine-induced expression of CCL2 and ICAM-1 in RA FLSs. In addition, hydroxymethylation of the ICAM-1 promoter region was dependent on TET3. These results suggest that continuous exposure to inflammatory cytokines results in leaving an inflammatory memory in FLS in a TET3-dependent manner, thereby promoting pannus formation and increasing the probability of joint destruction.

Disclosure of Interest: A. Kawabe: None declared, K. Naknao: None declared, K. Sakata: None declared, K. Yamagata: None declared, S. Nakayamada: None declared, Y. Tanaka Grant/research support from: Y. Tanaka, has received consulting fees, speaking fees, and/or honoraria from Abbvie, Chugai, DaiichiSankyo, Bristol-Myers, Mitsubishi-Tanabe, Astellas, Takeda, Pfizer, Teijin, Asahikasei, YL Biologics, Sanofi, Janssen, Eli Lilly, GlaxoSmithKline and has received research grants from Mitsubishi-Tanabe, Takeda, Daiichi-Sankyo, Chugai, BristolMyers, MSD, Astellas, Abbvie, Eisai

DOI: 10.1136/annrheumdis-2017-eular.3613

\section{FRI0032 CURATIVE EFFECT OF CAMELLIA SINENSIS (CS) AGAINST OPPORTUNISTIC INFECTION IN VULNERABLE ANIMAL MODEL OF RHEUMATOID ARTHRITIS}

A. Tanwar ${ }^{1,2}$, R. Chawla ${ }^{2}$, M. Basu ${ }^{2}$, R. Arora ${ }^{3}$, H.A. Khan ${ }^{1} .{ }^{1}$ Heavy metal and Clinical Toxicology Laboratory, Department of Medical Elementology and Toxicology, Jamia Hamdard, New Delhi; ${ }^{2}$ Division of CBRN Defence, Institute of Nuclear Medicine and Allied Sciences (INMAS): ${ }^{3}$ Office of DG (LS), Defence Research and Development Organisation, DRDO Bhawan, Delhi, India

Background: Rheumatoid arthritis (RA) is an autoimmune disease characterised by chronic inflammation of pro-inflammatory cytokines. Opportunistic infection plays a significant role in loss of tolerance to citrullinated proteins along with inflammatory progression of RA. Due to the immunosuppressive property of anti-rheumatic drugs, the patients of RA become highly vulnerable to microbial infections [1]. Thus, the present study employed an in vivo animal model to explore the holistic remedies for the effective treatment of RA.

Objectives: To study the immunomodulatory effect of Camellia sinensis (Cs) against inflammatory disorder

Methods: Study utilized collagen induced arthritis (CIA) rat model with Salmonella typhimurium $\left(10^{8} \mathrm{CFU} / \mathrm{ml}\right.$, p.o) as an opportunistic infectious agent which was introduced to enhance disease severity (on 21st day)[2]. Treatment with Cs at oral dose $400 \mathrm{mg} / \mathrm{kg} / \mathrm{body}$ wt. (p.o) was started from 21 st day for 14 days to explore its curative, anti-edematogenic effect and quantitation of oxidative stress markers. To validate biochemical changes, the histopathologiy and level of cytokines were also studied in joint tissue followed by 7 Tesla Magnetic Resonance Imaging (7T MRI).

Results: Treatment groups significantly restored the level of oxidative stress markers (Table-1). Furthermore, there was significant reduction in the number of bacterial colonies in blood and fecal matter in the treatment group as compared to infected group, while pro-inflammatory cytokine level of TNF- $\alpha$, IL-1, IL-6 was significantly lower in joint tissue. Histological \& 7T-MRI changes in the treatment group included significant reduction of cartilage erosion \& pannus formation and there were no signs of inflammation in the small intestine as compared to arthritic and infected group (Figure 1)

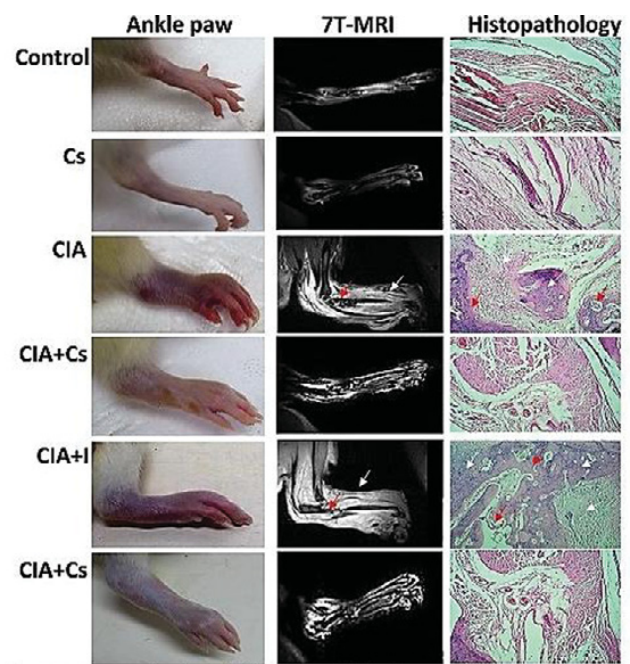

Fig 1: Comparative evaluation of 7T MRI and histology of rat ankle joints: Treatment group (CIA $+\mathrm{Cs}$, $\mathrm{ClA}+\mathrm{I}+\mathrm{Cs}$ ) showed less tissue swelling (white arrows), bone and cartilage erosions (red arrows) as compared to infected groups (CIA, CIA+I) and there was no significant change in between control and $\mathrm{Cs}$ only groups.

Conclusions: The present study demonstrated that Cs has anti-inflammatory effect and could also be used as potent immunomodulator to manage RA. References:

[1] R. Fleischmann, et al, Efficacy and safety of tofacitinib in patients with active rheumatoid arthritis: review of key Phase 2 studies, Int. J. Rheum. Dis. (2016). doi:10.1111/1756-185X.12901.

[2] D.D. Brand, et al Rosloniec, Collagen-induced arthritis, Nat. Protoc. 2 (2007) 1269-1275. doi:10.1038/nprot.2007.173.

Acknowledgements: Authors are greatful to VC, Jamia Hamdard and Director, INMAS for providing research facility and support.

Disclosure of Interest: None declared

DOI: 10.1136/annrheumdis-2017-eular.1057

Abstract FRI0032 - Table 1. Effect of Cs on oxidative stress markers

\begin{tabular}{|c|c|c|c|c|c|c|}
\hline S. No & Control & Cs & CIA (Arthritic) & $\mathrm{ClA}+\mathrm{Cs}$ (Treatment) & $\mathrm{ClA}+\mathrm{I}$ (Infected) & $\mathrm{ClA}+\mathrm{I}+\mathrm{Cs}$ (Treatment) \\
\hline Glutathione ( $\mu$ moles of GSH/g tissue) & $1.29 \pm 0.042$ & $1.69 \pm 0.02$ & $0.51 \pm 0.26^{*}$ & $1.40 \pm 0.06^{\# \#}$ & $0.56 \pm 0.032^{*}$ & $1.45 \pm 0.034^{\#}$ \\
\hline Lipid peroxidation ( $\mu$ moles of TBARS formed $/ \mathrm{hr} / \mathrm{g}$ tissue) & $1.40 \pm 0.0095$ & $1.33 \pm 0.023$ & $2.09 \pm 0.073^{\star}$ & $1.80 \pm 0.055^{\# \#}$ & $2.32 \pm 0.043^{\star}$ & $1.73 \pm 0.073^{\# \#}$ \\
\hline Articular elastase (ng/g protein) & $135 \pm 5.00$ & $136 \pm 4.50$ & $250 \pm 0.13^{\star}$ & $182 \pm 1.00^{\# \#}$ & $242 \pm 0.3^{*}$ & $193 \pm 2.5^{\# \#}$ \\
\hline Superoxide dismutase (nmoles of epinephrine protected from oxidation $/ \mathrm{min} / \mathrm{mg}$ protein) & $2.20 \pm 0.085$ & $2.21 \pm 0.082$ & $1.84 \pm 0.135^{\star}$ & $2.35 \pm 0.80^{\#}$ & $1.69 \pm 0.05^{*}$ & $2.63 \pm 0.1^{\# \#}$ \\
\hline Nitric oxide ( $\mu$ moles nitrite/mg wet tissue) & $0.44 \pm 0.03$ & $0.39 \pm 0.065$ & $0.97 \pm 0.1^{*}$ & $0.66 \pm 0.2^{\#}$ & $0.95 \pm 0.4^{\star}$ & $0.73 \pm 0.03^{\#}$ \\
\hline Catalase ( $\mu$ moles of $\mathrm{H} 2 \mathrm{O} 2$ consumed $/ \mathrm{min} / \mathrm{mg}$ protein) & $161 \pm 2.94$ & $144 \pm 3.10$ & $39 \pm 0.005^{\star}$ & $106 \pm 1.00^{\# \#}$ & $37 \pm 2.00^{*}$ & $82 \pm 1.50^{\# \#}$ \\
\hline
\end{tabular}

All the values expressed in Mean \pm SD $(n=6)$; Significant differences indicated by ${ }^{\#} p<0.05$ and ${ }^{\# \#} p<0.01$ as compared to CIA and CIA+I group and ${ }^{*} p<0.001$ as compared to control group. 